\title{
The very early thermal state of Terra Cimmeria: Implications for magnetic carriers in the crust of Mars
}

\author{
Javier Ruiz
}

Centro de Biología Molecular, CSIC-Universidad Autónona de Madrid, 28049 Gantoblanco, Madrid, Spain

\begin{abstract}
A B S T R A C T
Large areas of strongly magnetized crust are located in Terra Cinımeria and Terra Sirenun, in the southern highlands of Mars, the older terrains on the planet. The typical depth to the base of the magnetized layer, deduced from the magnetic spectrum of Mar's and modeling of isolated magnetic anomalies, would $\sim 40-60 \mathrm{~km}$. In this paper the thelmal state of Terra Cimmeria is revisited by calculating heat flows and crustal geotherms consistent with a previous estimation of the effective elastic thickness of the lithosphere, and with crustal abundances of heat-producing elements based on surface measurements performed by the Mars Odyssey Gammia Ray Spectrometer. The results suggest that, at the time of formation of the magnetized terrains sufface (which have a minimum age of $4.1 \mathrm{Ga}$ ), Curie depths for magnetite and hematite were shallowel and similar, respectively, than the typical depth to the base of the magnetized layer. This implies that hematite is an important (if not dominant) contributor to the magnetization of the martian crust. However, an early walm climate would enhance the chance of magnetite to be a significant, even dominant, magnetization carlier in the lower portion of the magnetic layel.
\end{abstract}

\section{Introduction}

The largest and strongly magnetized terrains on Mars are located in Terra Cimmeria and Terra Sirenum (e.g., Acuña et al., 1999; Connerney et al., 2001), regions which are part of the southern cratered highlands (Fig. 1), the oldest terrains on Mars. Currently there is not a core magnetic field in Mars, which implies that the observed crustal magnetism is remanent. Moreover, the absence of significant magnetization on the large impact basins Hellas, Isidis and Argyre, which are superimposed on the highlands, indicates that the martian dynamo was inactive, or very weakly active, when these basins formed, since the crust was not subsequently remagnetized (e.g., Acuña et ąl., 1999; Mohit and Arkani-Hamed, 2004).

There are evidences suggesting a significant depth to the base of the magnetized layer. Studying the demagnetization caused by impact craters, Nimmo and Gilmore (2001) suggested that the base of the magnetized layer was more likely $\sim 30-40 \mathrm{~km}$ deep, although uncertainties in this approach were large, and values between 10 and $100 \mathrm{~km}$ are admissible The difference of magnetization intensity between southern highlands and northern lowlands, which have a thinner crust (Neumann et al., 2004), also suggests that the strongest magnetization is deeply placed in the highlands crust (Arkani-Hamed, 2002). In this sense, Mitchell et al. (2007) have found a correlation between magnetic anomalies in the northern lowland and locally thicker crust. From the magnetic spectrum of Mars, Voorhies et al. (2002) deduced an average thickness of $\sim 50 \mathrm{~km}$ for the magnetic crust. A refined study by Voorhies (2008) favored a typical depth of $47.8 \pm 8.4 \mathrm{~km}$ for base of the magnetized layer. Finally, modeling of three isolated anomalies in Terra Sirenum has obtained magnetization depths of $\sim 55, \sim 58$, and $\sim 31 \mathrm{~km}$ (Quesnel et al., 2007), the two first values being consistent with the results of Voorhies (2008).

Thermoremanent magnetization is formed when a magnetic mineral is cooled (in presence of a magnetic field) through its blocking temperature, which is usually within $\sim 100^{\circ} \mathrm{C}$ of the curie temperature. The thickness of the potentially magnetized crust is therefore limited by the shallower depth to the Curie temperature, since the time when the magnetization was established, of the minerals that carry the magnetization. The age of the surface of the strongly magnetized highlands and it of the dynamo cessation are similar (see Frey, 2006; Lillis et al., 2008; Werner, 2008). In absence of a core field, the remagnetization of a cooling lower crust by local magnetic fields originated from preexistent crustal magnetic sources does not contributes significantly to the large scale magnetic anomalies observed on the highlands (Arkani-Hamed, 2007). This implies that magnetization depths deduced by Voorhies (2008) and Quesnel et al. (2007) are representative for the time when the magnetized highlands terrains were formed.

There is not consensus about the nature of the magnetic carrier and pyrrhotite, magnetite (including titanomagnetite) and 


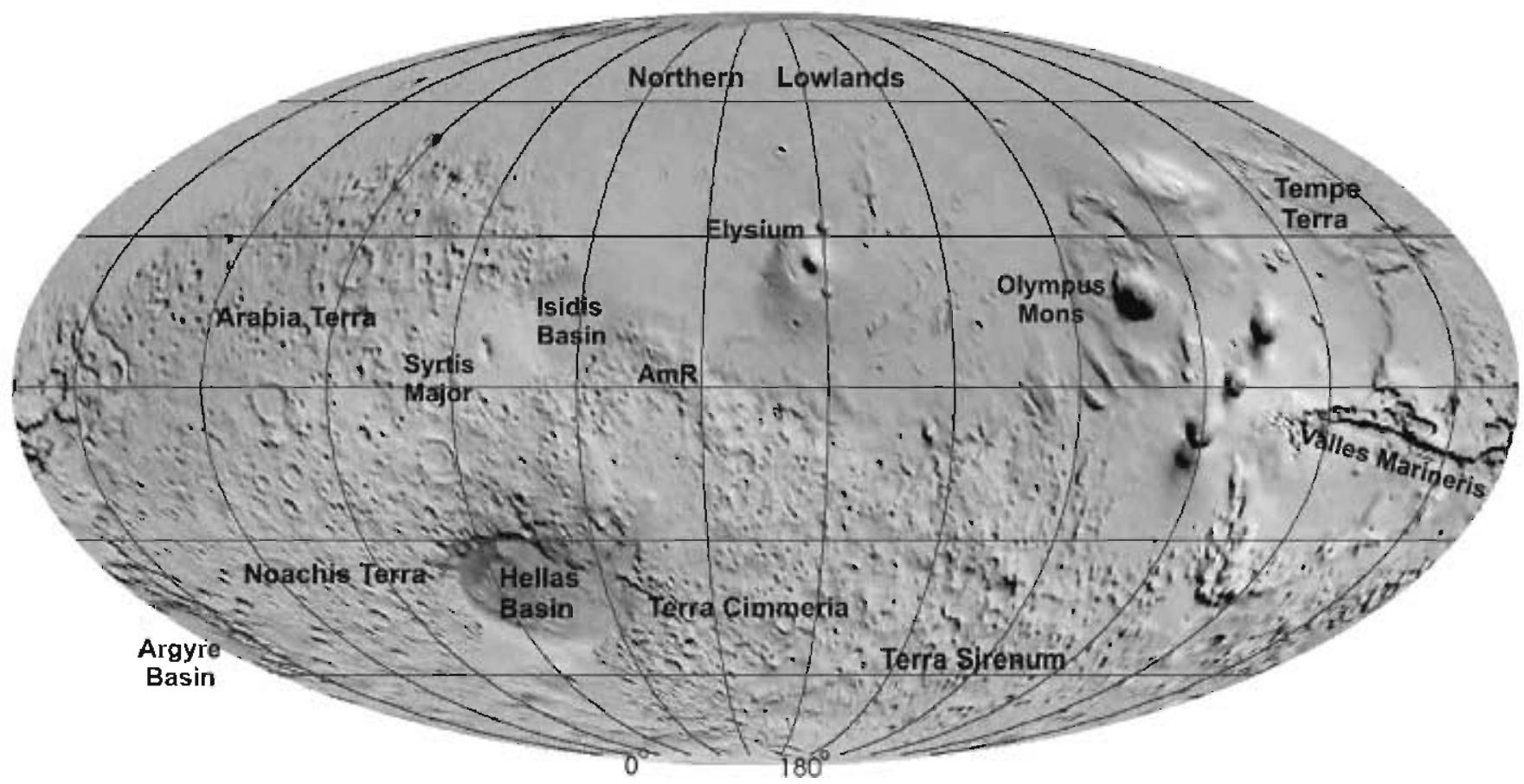

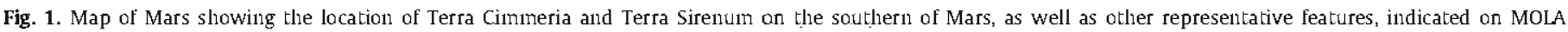
topography.

(e.g., Kletetschka et al., 2000; Rochette et al., 2001; Dunlop and Arkani-Hamed, 2005). Considerations based on heat flow and acceptable geotherms for the time of magnetization make pyrrhotite to unlikely be the dominant magnetic carrier, because their low Curie temperature $\left(\sim 325^{\circ} \mathrm{C}\right)$ would imply a depth to the base of the magnetized layer substantially lower than the suggested by the evidences above revised (Ruiz et al., 2006; Arkani-Hamed, 2007). A similar argument can be used for discard titanomagnetite as an important magnetic carrier in the martian crust.

A previous work (Ruiz et al., 2006) analyzed the early thermal state of several locations on the southern highlands, with special attention to the potential depth of magnetization in Terra Cimmeria. Heat flows and temperature profiles were calculated from the effective elastic thickness of the lithosphere obtained by McGovem et al. $(2002,2004)$, and crustal heat sources were included by assuming that these heat sources represent a given fraction of the total surface heat flow. Measurements of potassium and thorium abundances obtained by Mars Odyssey Gamma Ray Spectrometer (GRS) (Taylor et al., 2006), permit revisiting the very early thermal state of Terra Cimmeria, and their implications for crustal magnetization depth and potential magnetic carriers on a much more robust basis. This is precisely the motivation of this paper. Thus, I calculate surface heat flows from the effective elastic thickness and heat-producing elements abundances based on GRS measurements (uranium abundance is calculated from cosmochemical arguments). Next, we calculate Curie depths for magnetite and hematite for the time when the topography of the magnetized highlands terrains was formed, in order to obtain information on the nature of the carrier of crustal magnetism.

\section{Heat flows and temperature profiles}

Through the gravity/topography admittance analysis of northeast Terra Cimmeria (in an area centered on $30^{\circ} \mathrm{S}, 180^{\circ} \mathrm{E}$, and therefore in the strongly magnetized highlands), McGovern et al. (2002, 2004) obtained an effective elastic thickness lower than $12 \mathrm{~km}$ for this region. The effective elastic thickness is a measure of the total strength of the lithosphere, which integrates contributions from brittle and ductile layers and from elastic cores of the lithosphere (for a review see Watts and Burov, 2003). Effective elastic thicknesses can be converted to heat flows following the equivalent strength envelope procedure described by McNutt (1984). This methodology is based on the condition that the bending moment of the mechanical lithosphere must be equal to the bending moment of the equivalent elastic layer of thickness $T_{e}$, and so,

$\frac{E K T_{e}^{3}}{12\left(1-v^{2}\right)}=\int_{0}^{T_{\mathrm{m}}} \sigma(z)\left(z-z_{n}\right) \mathrm{d} z$,

where $E$ is the Young's modulus, $K$ is the topography curvature, $T_{e}$ is the effective elastic thickness, $v$ is the Poisson's ratio, $T_{m}$ is the mechanical thickness of the lithosphere, $\sigma(z)$ is the least, at depth $z$, of the brittle (frictional failure) strength, the ductile (temperature-dependent creep) strength, or the fiber stress (which is due to plate flexure), and $z_{\mathrm{n}}$ is the depth to the neutral stress plane. Additionally, the condition of zero net axial force is imposed,

$\int_{0}^{T_{\mathrm{m}}} \sigma(z) \mathrm{d} z=0$

The base of the mechanical lithosphere is defined as the depth at which the strength reaches a low value, usually taken as $50 \mathrm{MPa}$ (McNutt, 1984) or 10 MPa (Ranalli, 1994), and below which there are no further significant increases in strength. Brittle strengths, due to its dependence on gravity, are lower for Mars than for Earth, which in turn implies lower total strengths for Mars, and for this we chose $10 \mathrm{MPa}$ as the strength level defining the base of the martian mechanical lithosphere (Ruiz et al., 2006), although the exact value selected does not produce significant changes in the calculations due to the exponential dependence of ductile strength on temperature.

Brittle deformation dominates in the upper part of the lithosphere, whereas ductile creep dominates in the lower one. The brittle strength is calculated according to the expression (e.g., Ranalli, 1997) 
There have been suggestions of an early martian climate wet where $\alpha$ is a coefficient depending on the stress regime, $\rho$ is the density, $g$ is the acceleration due to the gravity ( $3.72 \mathrm{~ms}^{-2}$ for Mars) $\lambda$ is the pore pressure, and $z$ is the depth. The topography curvature of northeast Terra Cimmeria is concave downward (see below), which implies that the part of the elastic plate above the neutral stress plane is under tension (e.g., Turcotte and Schubert, 2002). For this reason $\alpha=0.75$, value adequate for pure tension (e.g., Ranalli, 1997), is used in Eq. (3). The topography/admittance study by McGovern et al. (2004) found best-fit crustal densities of 2950$3000 \mathrm{~kg} \mathrm{~m}^{-3}$ for Terra Cimmeria. Similarly, McKenzie et al. (2002) found a best-fit crustal density of $2970 \mathrm{~kg} \mathrm{~m}^{-3}$ for the southern highlands taken as a whole (McKenzie et al., 2002). Thus, a density value of $2975 \mathrm{~kg} \mathrm{~m}^{-3}$ is used here, but increasing or decreasing this value by $25 \mathrm{~kg} \mathrm{~m} \mathrm{~g} \mathrm{~m}^{-3}$ does not alter significantly the results. Finally, the nominal calculations are performed for zero pore pressure $(\lambda=0)$, but the effect of a hydrostatic pore pressure will be also considered.

The ductile strength (which does not depend on the stress regime) is given by

$\left(\sigma_{1}-\sigma_{3}\right)_{d^{\prime}}=\left(\frac{\dot{e}}{A}\right)^{1 / n} \exp \left(\frac{Q}{\pi R T}\right)$,

where $\mathrm{e}$ is the strain rate, $A, Q$ and $n$ are laboratory-determined constants, $R\left(=8.31447 \mathrm{~J} \mathrm{~mol}^{-1} \mathrm{~K}^{-1}\right)$ is the gas constant, and $T$ is the absolute temperature. Because the effective elastic thickness deduced for Terra Cimmeria is an upper limit, we only can obtain lower limits to surface heat flows. I therefore calculate ductile strength for a slow strain rate of $10^{-19} \mathrm{~s}^{-1}$, value usually taken as a reasonable lower limit for Mars (e.g., McGovern et al., 2002, 2004; Ruiz et al., 2008). For creep parameters of the martian crust I use the constants for the flow law of diabase: $A=0.0612 \mathrm{MPa}^{-n} \mathrm{~s}^{-1}, n=3.05$ and $Q=276 \mathrm{~kJ} \mathrm{~mol}{ }^{-1}$ (Caristan, 1982). The use of a "standard" wet diabase for the martian crust is consistent with extensive evidence for water-related geological activity in early Mars (eg., Head et al., 2001). The water amount needed for make "wet" the diabase is certainly modest (lower than 1 percent; see Caristan, 1982). This amount of water does not produce any appreciable effect on the pore pressure; although water was present in the martian crust, it is not clear if in sufficient amount to have an substantial influence on the brittle strength. Otherwise, a dry diabase rheology is hardly consistent with the comparison among the evolution of effective elastic thiclmess of the lithosphere and thermal history models for Mars (Grott and Breuer, 2007; Guest and Smrekar, 2007).

The fiber stress is in turn calculated from

$\sigma_{\text {fib }}=\frac{E K\left(z-z_{n}\right)}{1-v^{2}}$.

The elastic parameters are taken as $E=100 \mathrm{GPa}$ and $\nu=0.25$, while the topography curvature, obtained from the maximum value of the second derivative of the equivalent elastic layer, is $4.2 \times 10^{-7} \mathrm{~m}^{-1}$ and concave downward for northeast Terra Cimmeria (see Ruiz et al., 2006).

The link between strength envelope procedure and heat flow comes from the dependence of the ductile strength on temperature. Mars Odyssey GRS results suggest a martian crust much less geochemically varied than the Earth's crust (Taylor et al., 2006). Temperature profiles are therefore calculated by assuming radioactive heat sources homogeneously distributed in the crust: so, for a given depth $z$ the temperature is given by

$T_{z}=T_{s}+\frac{F z}{k}-\frac{H z^{2}}{2 k}$

where $T_{s}$ is the surface temperature, $F$ is the surface heat flow, $k$ is the thermal conductivity, and $H$ is the volumetric heat production rate.

and much warmer than the present-day one (e.g., Fanale et al., 1992), based on abundant evidences for Noachian geological features apparently related to liquid water availability on, and close to, the surface, including evidences for ancient oceans (see reviews by Clifford and Parker (2001) and Dohm et al. (2008), ). However, recent works have found evidences favoring a short duration for whichever potential wam and wet period (e.g., Lamb et al., 2008; Mustard et al., 2008; Som and Montgomery, 2008), which suggests that the martian climate has been usually cold. Also, low near-surface temperatures have been deduced for most of the past $4 \mathrm{Ga}$ from ALH84001 thermochronology (Shuster and Weiss, 2005). Thus, a surface temperature of $220 \mathrm{~K}$, the presentday mean surface temperature (Kieffer et al., 1977), is used in the nominal calculations, although the effect of a higher surface temperature is also considered.

For the thermal conductivity of the crust, values between 2 and $3 \mathrm{~W} \mathrm{~m} \mathrm{~m}^{-1} \mathrm{~K}^{-1}$ are used. A value of $2 \mathrm{Wm}^{-1} \mathrm{~K}^{-1}$ is appropriate for basaltic rocks (e.g., Beardsmore and Cull, 2001; Grott et al., 2005) and for a wide variety of crustal rocks at temperatures of several hundreds of degrees centigrade (e.g., Bonner et al., 2003), but numerous works have used a value of $2.5 \mathrm{~W} \mathrm{~m}^{-1} \mathrm{~K}^{-1}$ (Solomon and Head, 1990; McGovern et al., 2002, 2004; Ruiz et al., 2006), typical for terrestrial continental crust, or even $3.2-3.3 \mathrm{~W} \mathrm{~m}^{-1} \mathrm{~K}^{-1}$ (Anderson and Grimm, 1998; Schultz and Watters, 2001).

The crustal volumetric heating rate depends on both the amount of heat-producing elements and time before present. Measurements of potassium and thorium abundances, as well as $k$ /Th ratios, show a wide variation on the surface (Taylor et al., 2006). Here I use crustal potassium and thorium abundances of 3630 and $0.70 \mathrm{ppm}$, respectively, average values deduced from GRS data for the ancient southern highlands (Taylor et al., 2006). For uranium abundance, we use a Th/U ratio of 3.6 deduced from SNC meteorite geochemistry (McLennan, 2003). For the absolute age of formation of the topography of the magnetized highlands values of 4.1 and 4.5 Ga are considered. The lower limit corresponds to the minimum age of the magnetized highlands surface according to crater counts (Werner, 2008 , and is consistent with the time of martian dynamo death deduced from counting of visible and buried impact craters in magnetized and non-magnetized large impact basins (Frey, 2006; Lillis et al., 2008); this absolute age value is based on the cratering chronology of Hartmann and Neukum (2001). There is not available an upper limit for the age of Terra Cimmeria, and the value used here for this purpose is largely generous, since it is slightly younger than Mars fomation. Volumetric heat production rates are calculated for a crustal density of $2975 \mathrm{~kg} \mathrm{~m}^{-3}$, and decay constants from Van Schmus (1995), obtaining volumetric heat production rates between 0.66 and $0.84 \mu \mathrm{W} \mathrm{m}^{-3}$ for 4.1 and $4.5 \mathrm{Ga}$, respectively, although in the calculations I use rounded values of 0.65 and $0.85 \mu \mathrm{W} \mathrm{m}^{-3}$.

Surface heat flows and temperature profiles are obtained by simultaneously solving Eqs. (1)-(5). Fig. 2 shows that the heat flow increase for higher thermal conductivities and heat production rates. As above stated, the calculated heat flows are lower limits, since the effective elastic thickness value available for this region is an upper limit. For equal heat dissipation rates heat flows in this work are similar, although slightly higher, to those obtained by Ruiz et al. (2006).

\section{Depth to the curie temperature}

Heat flows in Fig. 2 can be used in Eq. (1) in order to calculate Curie depths. In the calculations I use Curie temperatures of 580 and $670^{\circ} \mathrm{C}$ for magnetite and hematite, respectively (titanomagnetite and titanohematite have Curie temperatures lower than pure magnetite and hematite, respectively). Fig. 3 shows Curie depths 


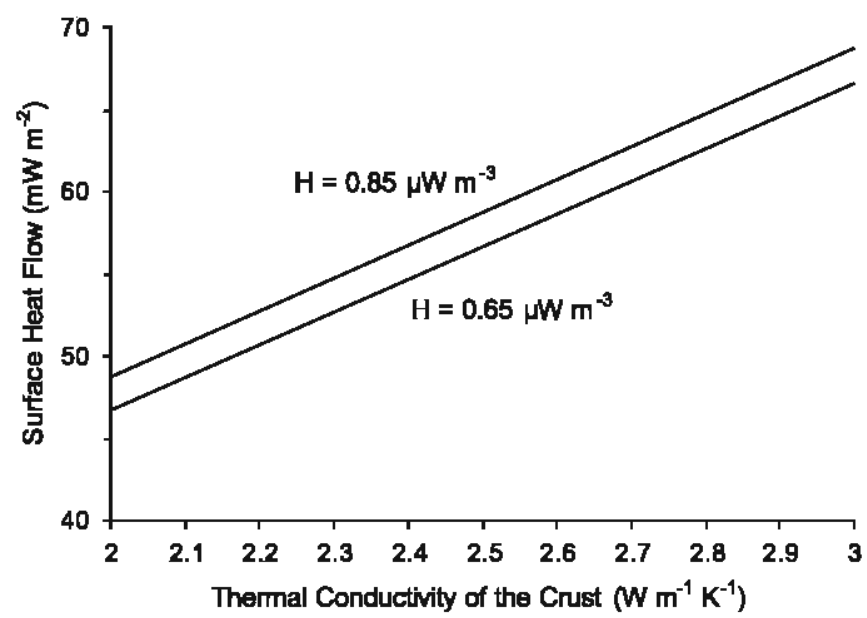

Fig. 2. Surface heat flow obtained for $T_{e}=12 \mathrm{~km}, K=4.2 \times 10^{7}{ }^{7 n}{ }^{1}$ and $H=0.65$ and $0.85 \mu \mathrm{W}_{\mathrm{n}}{ }^{3}$, as a function of the thernal conductivity of the crust.

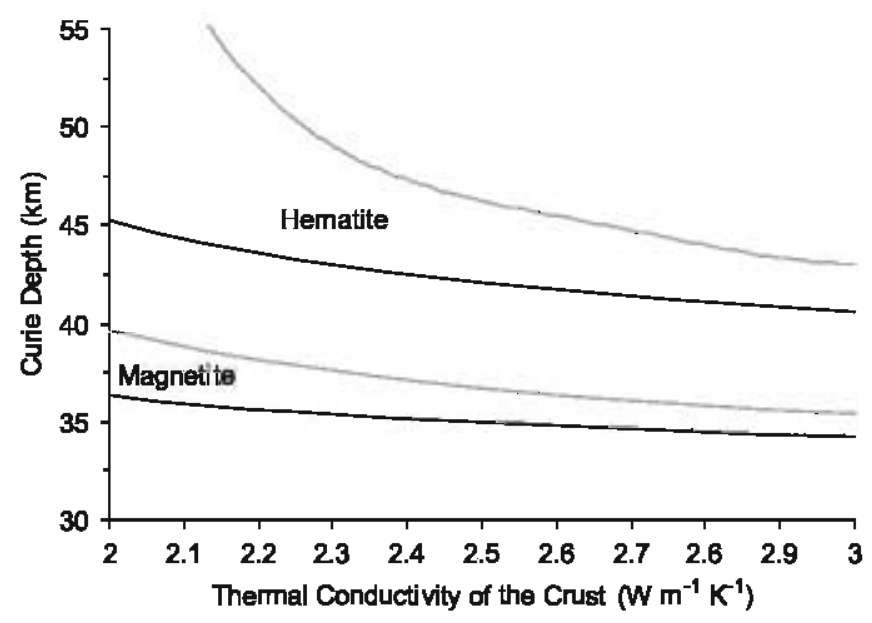

Fig. 3. Curie depths for magnetite and hematite as a function of the thermal conductivity of the crust, calculated from heat flows in Fig. 1. Black and gray curves indicate crustal heat production rates of 0.65 and $0.85 \mu \mathrm{W} \mathrm{m}^{3}$, respectively.

for magnetite and hematite (Curie depths for pyrrhotite are always below $\sim 20 \mathrm{~km}$, which seem unreasonably low for martian crustal magnetism; see also Ruiz et al., 2006). Curie depth decreases for higher thermal conductivity (or, equivalently, for higher heat flow). For magnetite, the base of the potentially magnetized layer is lower than the typical depth to the base of the magnetized layer obtained by Voorhies (2008) from the magnetic spectrum of Mars. Also, our nominal results for magnetite are only consistent with the depth to the base of the magnetized layer obtained for one of the isolated anomalies analyzed by Quesnel et al. (2007). Otherwise, Curie depths for hematite are consistent with available constraint for magnetization depths in the highlands.

Minimum historical Curie depths obtained by the thermal history models of Arkani-Hamed (2005) and Dunlop and ArkaniHanled (2005) are larger (generally higher than $\sim 50$ and $\sim 60 \mathrm{kml}$ for magnetite and hematite, respectively) than those obtained in the present work. But calculations based on the effective elastic thickness of the lithosphere probe the thermal conditions during the formation of specific regions, whereas thermal history models deal usually with planetary averages.

The case for $k=2 \mathrm{~W} \mathrm{~m}^{-1} \mathrm{~K}^{-1}$ gives lower heat flows and cooler geotherms. This case is therefore useful for evaluate maximum Curie depths at the time when the crustal magnetization formed.
Fig. 4 shows the Curie depth as a function of Curie temperature for $k=2 \mathrm{~W} \mathrm{~m}^{-1} \mathrm{~K}^{-1}$, and values of 0.65 and $0.85 \mu \mathrm{Wm}^{-3}$ for the heat production rate. Also represented are lower and upper limits for the typical thickness of the magnetized crust. For a fixed effective elastic thickness, higher crustal heat production rates give higher surface heat flows, but lower temperatures at the lower crust (Ruiz et al., 2006). The curve for $0.85 \mu \mathrm{W} \mathrm{m} \mathrm{m}^{-3}$ is only represented until a depth of $57 \mathrm{~km}$. For higher crustal thickness, the contribution to the surface heat flow due to radioactive crustal sources is higher than the surface heat flow, implying a negative mantle heat flow. The distribution of $U$, Th and $K$ in the crust could be stratified, with lower abundances in the lower crust. In this case, temperature profiles in the lower crust should be more linear than in the upper crust, and Curie isotherms shallower. Thus, the case represented in Fig. 4 is useful to obtain upper limits for Curie depth as a function of Curie temperature (Interestingly, $57 \mathrm{~km}$ is a value similar to the average thickness of the southern highlands crust in the crustal models of Neumann et al. (2004), and would consistent with the possibility of a relatively low mantle heat flow, at least for certain epochs (Ruiz et al., 2008), although these question are beyond the scope of this paper). From Fig. 4 it is clear that, for the nominal calculations, potential magnetic carriers consistent with estimations of the typical depth to the base of the magnetized layer must include high Curie temperature minerals. In fact, magnetite would only be marginally consistent with typical depths for the base of the magnetized crust for $0.85 \mu \mathrm{Wm}^{-3}$ (which is, as above mentioned, a very generous upper limit for the heat production rate).

Thermoremanent magnetization of magnetite decrease with increasing grain size (e.g., Dunlop and Arkani-Hamed, 2005; Kletetschka et al., 2005), and it is difficult to preserve the required small grain size in the deep crust (Kletetschka et al., 2005), which would be consistent with hematites being a significant magnetic carrier in the lower part of the magnetized layer. However, it is worth mentioning that magnetite would require lower concentrations than hematite to justify the observed anomalies (e.g., Dunlop and Arkani-Hamed, 2005).

Fig. 5 shows the Curie depth as a function of Curie temperature for $k=2 \mathrm{Wm}^{-1} \mathrm{~K}^{-1}$, same heat production rates, and a surface temperature of $273 \mathrm{~K}$ The surface heat flows are $\sim 5 \mathrm{~mW} \mathrm{~m}^{-2}$ lower than in the case for $T_{s}=220 \mathrm{~K}$. Curves for 0.65 and $0.85 \mu \mathrm{W} \mathrm{m}^{-3}$ are represented until depths of 64 and $51 \mathrm{~km}$, respectively, since

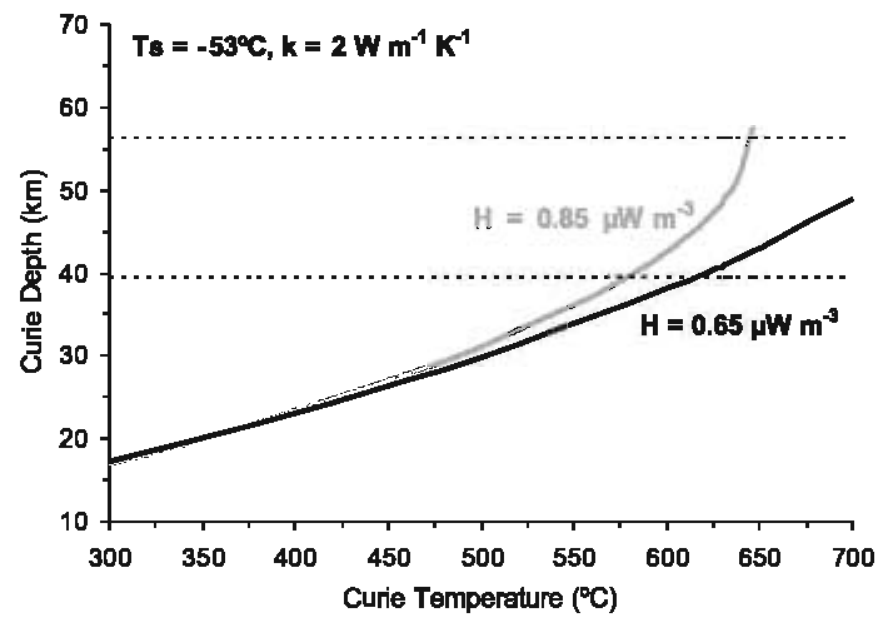

Fig. 4. Curie depth as a function of Curie temperature calculated for $k=2 \mathrm{~W} \mathrm{n}^{1} \mathrm{~K}^{1}$, crustal heat production rates of 0.65 and $0.85 \mu \mathrm{W}_{1 \mathrm{n}}{ }^{3}$, and a surface temperature equal to the present-day average value Dotted lines indicate lower and upper linits for the bypical thickness of the magnetized crust deduced from the magnetic spectrum of Mars by voorhies (2008). 


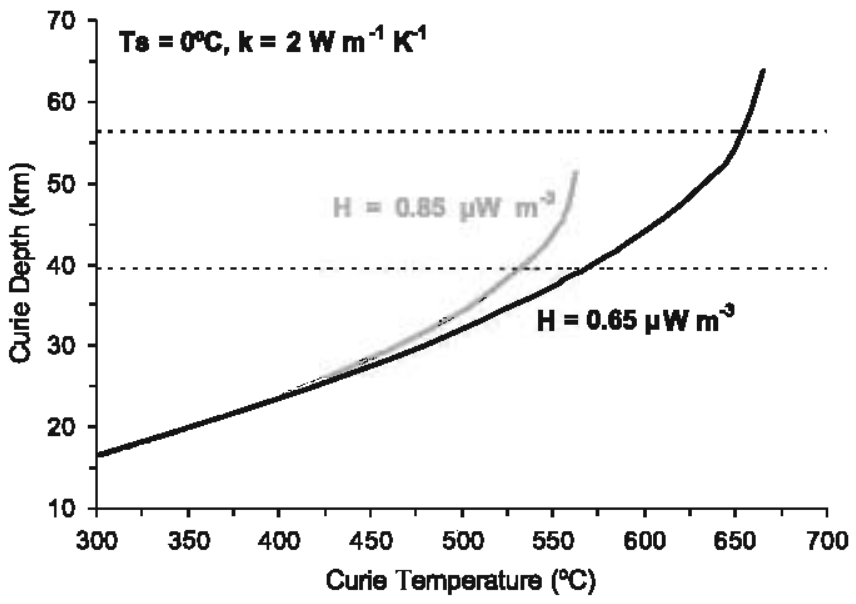

Fig. 5. Curie depth as a function of Curie temperature calculated for $k=2 \mathrm{Wn}^{1} \mathrm{~K}^{\mathrm{l}}$, crustal heat production rates of 0.65 and $0.85 \mu \mathrm{W} \mathrm{n}^{3}$, and a surface tenperature of $0^{\circ} \mathrm{C}$, which may be adequate for a possible wann and wet early inartian clinate. Dotted lines indicate lower and upper linits for the bypical thickness of the nagnetized crust.

higher crustal thicknesses imply negative mantle heat flows. Curie temperatures between $\sim 530$ and $\sim 650^{\circ} \mathrm{C}$ are consistent with the typical depth to the base of the magnetized layer deduced from the magnetic spectrum of Mars. So, an early warm climate would enlarge the chance of magnetite or titanohematite, as an important magnetic carrier in the lower portion of the magnetized crust.

An early warm climate could be associated to an substantial amount of liquid water amount in the early martian crust. Fig. 6 shows the Curie depth as a function of Curie temperature for the same conditions of the Fig. 5 but considering hydrostatic pore pressure (calculated as the ratio between water and crust densities). This implies a decreasing of the brittle strength. In order to satisfying the condition imposes by Eq. (1), heat flows are also decreased, since the reduction in brittle strength must be compensated through of increasing the ductile strength. So, this scenario, although speculative, put a generous upper limit to the Curie depths for magnetite and hematite. The surface heat flows are $\sim 2 \mathrm{~mW} \mathrm{~m}^{-2}$ lower than in the respective cases represented in Fig. 5, and curves for 0.65 and $0.85 \mu \mathrm{Wm}^{-3}$ are represented until depths of 60 and $49 \mathrm{~km}$, respectively, (higher crustal thicknesses would imply negative mantle heat flows), and curie temperatures between $\sim 490$ and $\sim 590^{\circ} \mathrm{C}$ are consistent with the typical depth to the base of the magnetized layer. Thus, if an early warm climate existed, and if there was a substantial amount of liquid water filling upper crust porosity, then magnetite should be the most probable magnetic carrier in the lower part of the magnetized crust.

Parmentier and Zuber (2007) have suggested that vigorous hydrothermal circulation could greatly enhance heat transfer through the upper crust. Hydrothermal cooling could only operate above the brittle-ductile transition (the depth at which brittle and ductile strengths are equal), since below porosity is mostly eliminate by viscous creep (Hanna and Phillips, 2006). The strength envelope procedure used here to calculate the heat flow and temperature profile is based on from the temperature dependence of the ductile strength, whereas the britle strength is not temperature-dependent (although vigorous hydrothermal cooling requires water saturated porosity, and hence significant pore pressure). For a given effective elastic thickness, the temperature profile deduced for the crust below the brittle-ductile transition depth is independent of the temperature profile above, and therefore independent of if the upper crusts is, or not, cooled by hydrothermal circulation. Thus, the possibility of hydrothermal cooling does not influence Curie depths calculated in this work, although there would have

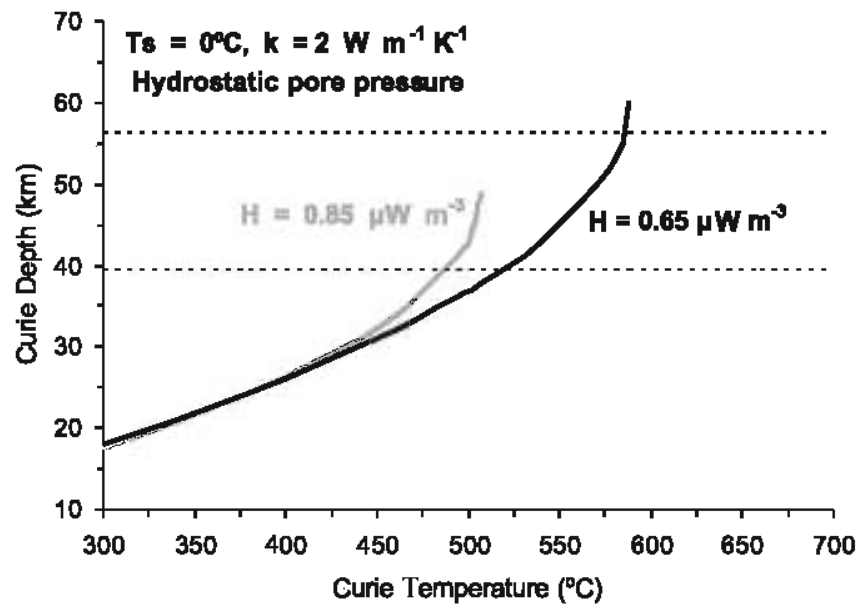

Fig. 6. Curie deptl as a function of Curie temperature calculated for $k=2 \mathrm{Wm}^{1} \mathrm{~K}^{1}$, crustal heat production rates of 0.65 and $0.85 \mu \mathrm{W} \mathrm{m}^{3}$, a surface temperature of $0^{\circ} \mathrm{C}$, and liydrostatic pore pressure. Dotbed lines indicate lower and upper limits for the typical thickness of the nagnetized crust.

differences in both the value of the surface heat flow and in the exact form of the upper crust thermal profile would be different.

\section{Conclusions}

Our results for the nominal calculation clearly support that high Curie temperature minerals, such as hematite, significantly contribute to (or even dominate) the crustal magnetism of Mars. The calculate Curie depths are upper limits (since heat flows are lower limits), which reinforce this conclusion. Thus, although magnetite may be an important mineral carrying magnetization in the martian crust, our results suggest that hematite should also be taken into account for the understanding of the magnetism of the southern highlands of Mars.

On the other hand, a warm early surface environment enhances the chance of magnetite to be an important magnetic carrier in the lower portion of the magnetized crust. An early climate for Mars is an attractive possibility, but remains controversial. If a warm early climate actually existed, and if it was associated with significant liquid water pore pressure in the upper crust, then magnetite should be the main magnetic carrier in the lower part of the magnetized layer. Future works on the climatic evolution of Mars could therefore provide important clues on the minerals carrying magnetization in the martian crust.

\section{Acknowledgments}

The author thanks Valle López and the VLOP group for your encouragement, and Gunther Kletetschka and an anonymous reviewer for your comments and suggestions. This work was supported by a contract Juan de la Cierva for Earth Sciences, cofinanced from the Ministerio de Ciencia e Innovación of Spain and the European Social Fund.

\section{References}

Acuña, M.H., 12 colleagues, 1999. Global distribution of crustal inagnetization discovered by the Mars Global Surveyor MAG/ER experinent. Science 284, $790-$ 793.

Anderso1h, S., Grimin, R.E., 1998. Rift processes at the Valles Marineris, Mars: constraints fron graviby on necking and rate-depending strength evolution. J. Geoplyys. Res. 103, 11113-11124.

Arkani-Haned, J., 2002. Magnetization of the martian crust. J. Geophys. Res. 107. doi: $10.1029 / 2001 J E 001496$.

Arkani-Hamed, J., 2005. Magnetic crust of Mars. J. Geophys. Res. 110, E08005. doi: 10.1029/2004JE002397. 
Arkani-Haned, J., 2007. Magnetization of nartian lower crust: Revisited. J. Geoplyys. Res. 112, E05008. doi: 10.1029/2006]E002824.

Beardsnore, G.R., Cull, J.P., 2001. Crustal heat flow. A Guide to Measurement and Modelling. Cambridge University Press, Cambridge. $32.4 \mathrm{pp}$.

Bonner, J.L., Blackwell, D.D., Herrin, E.T., 2003. Thermal constraints on earthquake depths in California. Bull. Seismol. Soc. Ann. 93, 2333-2354.

Caristan, Y., 1982. The transitions from high temperature creep to fracture in Marylan diabase J. Geophys. Res. 87, 6781-6790.

Clifford, S.M., Parker, T.J., 2001. The evolution of the martian hydrosphere: implications for the fate of a Primordial Ocean and the current state of the Northern Plains. Icarus $154,40-79$.

Connerney, J.E.P., Acuña, M.H., Wasilewski, P.J., Kletetschıa, G., Ness, N.F., Rèıne, H. Lin, R.P., Mitchell, D.L., 2001. The global magnetic field of Mars and inplications for crustal evolution. Geoplyys. Res. Lett. 28, 4015-4018.

Dohm, J.M., 12 colleagues, 2008. GRS Evidence and the possibility of paleooceans on Mars, Planet. Space Sci., doi:10.1016/j.pss.2008.10.008

Dunlop, D.]., Arkani-Haned, J., 2005. Magnetic minerals in the martian lower crust J. Geoplyys. Res. 110, E12S04 doi: 10.1029/2005JE0024024

Fanale, F.P., Postawko, S.E., Pollack, J.B., Carr, M.H., Pepin, R.O., 1992. Mars: epochal climate cliange and volatile history. In: Kieffer, H.H., Jakosky, B.M., Snyder, CW., Mattlews, M.S. (Eds.). Mars. Univ. of Arizona Press, Tucson, pp. 11351179 .

Frey, H.V., 2006. Impact constraints on, and a chronology for, major events in early Mars history. J. Geoplyys. Res. 111, E08591. doi:10.1029/2005]E002449.

Grott, M., Breuer, D., 2007. The evolution of the martian elastic lithosphere and implications for crustal and inantle rheology. Icarus 186, 517-526.

Grott, M., Hauber, E., Werner, S.C., Kronberg, P., Neukunn, G., 2005. Higl heat flux on ancient Mars: Evidence from rift flank uplift at Coracis Fossae. Geoplıys. Res. Lett. 32, L21201. doi: 10.1029/2005GL023894.

Guest, A, Sinrekar, S., 2007. New constraint on the thermal and volatile evolution of Mars. Plyys. Eartlı Planet. Interiors 164, 161-176.

Hanna, J.C., Phillips, R.J., 2006. Hydrological modeling of the martian crust with application to the pressurization of aquifersInnpact constraints on, and a chronology for, najor events in early Mars history. J. Geoplyys. Res. 110, E01004. doi: $10.1029 / 2004$ JE002330.

Hartmann, W.K., Neukum, G., 2001. Cratering chronology and the evolution of Mars. Space Sci. Rev. 96, 165-194.

Head, J.W., Greeley, R., Golombek, M.P., Hartmann, W.K. Hauer, E., Jaumann, R. Masson, P., Neukun, G., Nyquist, L.E., Carr, M.H., 2001. Geological processes and evolution. Space Sci. Rev. 96, 263-292.

Kieffer, H.H., Martin, T.Z., Peterfreund, A.R., Jakosky, B.M., Miner, E.D., Palluconi, F.D. 1977. Thermal and albedo mapping of Mars during the Viking primary mission. J. Geopliys. Res. 82, 4249-4291.

Kletetschka, G., Wasilewski, P.J., Taylor, P.T., 2000. Mineralogy of the sources for magnetic anomalies on Mars. Meteorit. Planet. Sci. 35, 895-899.

Kletetschka, G., Ness, N.F., Connerney, J.E.P., Acuñ̃a M.H., Wasilewski, P.J., 2005 Grain size dependent potential for self generation of magnetic anomalies on Mars via thermoremanent maghetic acquisition and magnetic interaction of hematite and magnetite. Plyys. Ear th Planet. Inter. 148, 149-156.

Lamb, M.P., Dietrich, W.E., Aciego, S.M., DePaolo, D.J., Manga, M., 2008. Formation of Box Canion, Idaho, by Megaflood: Implications for seepage erosion on Eartlı and Mars. Science 320, 1067-1070.

Lillis, R.J., Frey, H.V., Manga, M., 2008. Rapid decrease in martian crustal magnetization in the Noachian: implications for the dynamo and climate of early Mars. Geoplyys. Res. Lett. 35, L14203. doi:10.1029/2008GL034338.

McGovern, P.J., Solomon, S.C., Smith, D.E., Zuber, M.T., Simons, M., Wieczorek, M.A. Phillips, R.J., Neumann, G.A. Alaronson, O. Head, J.W., 2002. Localized gravicy/ topograply admittance and correlation spectra on Mars: Inplications for regional and global evolution. J. Geoplyys. Res. 107, 5136. doi:10.1029/ 2002JE001854

McGovern, P.J., Solomon, S.C., Sinitl, D.E., Zuber, M.T., Sinons, M., Wieczorek, M.A. Phillips, R.J., Neumann, G.A., Aharonson, O., Head, J.W., 2004. Correction to Localized gravicy/topography admittance and correlation spectra on Mars:
Implications for regional and global evolution. J. Geoplyss. Res. 109, E07007. doi: $10.1029 / 2004$ JE002286.

McKenzie, D., Barnett, D.N., Ywan, D.L., 2002. The relationship berween martian gravity and topography. Earth Planet. Sci. Lett. 195, 1-16.

McLennan, S.M., 2003. Large-ion lithophile element fractionation during the early differentiation of Mars and the composition of the martian primitive mantle. Meteor. Plantet. Sci. 38, 895-904

McNutt, M.K., 1984. Lithos pheric flexure and thermal anomalies. J. Geopliys. Res. 89 , $11180-11194$.

Mitchell, D.L., Lillis, R.J., Li11, R.P., Connerney, J.E.P., Acuna, M.H., 2007. A global nap of Mars' crustal magnetic field based on electron reflectonnetry. J. Geophys. Res. 112, E01002. doi: 10.1029/2005]E002564.

Mohit, P.S., Arkani-Hamed, J., 2004. Impact demagnetization of the martian crust. Icarus $168,305-317$.

Mustard, J.F., 35 colleagues, 2008. Hydrated silicate minerals on Mars observed by the Mars Reconnaissance Orbiter CRISM instrument. Nature 454, 305-309.

Neunann, G.A., Zuber, M.T., Wieczorek, M.A., McGovern, P.J., Lemoine, F.G., Smith, D.E., 2004. The crustal structure of Mars from gravity and topograpliy. J. Geoplyys. Res. 109, E08002. doi: 10.1029/2004]E002262.

Nimmo, F., Gilmore, M.S., 2001. Constraints on the depth of magnetized crust on Mars from inpact craters. J. Geophys. Res. 106, 12315-12323.

Parmentier, E.M., Zuber, M.T., 2007. Early evolution of Mars with mantle compositional stratification or hydrothernal crustal cooling. J. Geophys. Res. 112, E02007. doi: 10.1029/2005]E002626.

Quesinel, Y., Langlais, B., Sotin, C. 2007. Local inversion of magnetic anomalies: Implications for Mars's crustal evolution. Planet. Space Sci. 55, 258-269.

Ranalli, G., 1994. Nonlinear flexure and equivalent mechanical thickiness of the lithosphere. Tectonophysics 240, 107-114.

Ranalli, G., 1997. Rheology of the lithosphere in space and tine. Geol. Soc. Spec. Pub. $121,19-37$.

Rochette, P., Lorand, J.P., Fillion, G., Sautter, V., 2001. Pyrrhotite and the remanent nagnetization of SNC meteorites: A changing perspective on martian 1nagnetisin. Earth Planet. Sci. Lett. 190, 1-12.

Ruiz, J., McGovern, P.J., Tejero, R., 2006. The early thermal and magnetic state of the cratered highlands of Mars. Earth Planet. Sci. Lett. 241, 2-10.

Ruiz, J., Fernández, C., Gomez-Ortiz, D., Dohın, J.M., López, V., Tejero, R., 2008. Ancient heat flow, crustal thickness, and lithospheric mantle rheology in the Anenthes region, Mars. Eartlı Planet. Sci. Lett. 270, 1-12.

Schultz, R.A., Watters, T.R., 2001. Forward mechanical modeling of the Anenthes Rupes thrust fault on Mars. Geopliys. Res. Lett. 28, 4659-4662.

Sliuster, D.L., Weiss, B.P., 2005. Martian surface paleotemperatures from thermochronology of meteorites. Science 309, 594-597.

Solomon, S.C., Head, J.W., 1990. Heterogeneities in the thickness of the elastic lithosphere of Mars: Constraints on heat flow and internal dynannics. J. Geopliys. Res. 95, 11073-11083.

Som, S., Montgomery, D., 2008. Scaling relationships of martian valley networks: Implications for the evolution of surface liabitability. Astrobiology 8,435 .

Taylor, G.J., 22 colleagues, 2006. Bulk composition and early differentiation of Mars. J. Geophys. Res. 111, E03\$10, doi:10.1029/2005]E002645. (Printed 112(E3), 2007).

Turcotte, D.L., Scliubert, G., 2002. Geodynamics, second ed. Cambridge University Press, Cambridge.

Van Schmus, W.R., 1995. Natural radioactivity of the crust and mantle. In: Alrens, T.J. (Ed.) Global Eartl Physics: A Handbook of Plhysical Constants. AGU Reference Shelf 1, Anerican Geoplyysical Union, Washington, D.C., pp. 283-291.

Voorhies, C.V., 2008. Thickness of the magnetic crust of Mars. J. Geopliys. Res. 113 E04004 doi: $10.1029 / 2007$ JE002928.

Voorhies, CV., Sabaka, T.J., Purucker, M., 2002. On magnetic spectra of Earth and Mars. J. Geopliys. Res. 107, 5034. doi:10.1029/2001JE001534.

Watts, A.B., Burov, E.B., 2003. Lithospheric strength and its relation to the elastic and seisthogenetic layer thickness. Earth Plantet. Sci. Lett. 213, 113-131.

Werner, S.C., 2008. The early martian evolution-constraints from basin formation age. Icarus 195, 45-60. 